\title{
Environmental Factors Influencing Malaria in Manipal, Southern Karnataka, India.
}

\author{
Garima Verma ${ }^{1}$, CNV.Sai Bharath ${ }^{2}$, Uday Narayan Yadav², Poshan Thapa ${ }^{2,}$ \\ Miti Judith Ogorchukwu ${ }^{2}$ \\ 1(Department of Public Health/Manipal University, India) \\ 2(Department of Public Health/Manipal University, India)
}

\begin{abstract}
Malaria is a vector borne communicable disease transmitted by the bite of infected female anopheles mosquito. Transmission of malaria vectors are driven by different environmental factors. Malaria is one of the major health problems in India including Karnataka. A qualatitative and quantitative study was conducted among the construction workers in their migratory settlements as well in their work site. The workers were interviewed in order to explore the environmental factors influencing Malaria. For quantitative study, data was collected from 90 respondents by snowball convenient sampling and qualitative information was collected by indepth interview of 20 respondents at four construction sites in and around Manipal. The quantitative and qualitative findings shows that that water stagnation, bare soil, thick vegetation, open tanks, tyres, containers, garbage disposal, sewage disposal and sullage, high temperature, high humidity,pre and post rainy season are the major environmental factors that causes malaria.
\end{abstract}

Keywords: malaria, environmental factors, migrants

\section{Introduction}

Malaria is one of the world's major micro-parasitic infections in humans. Globally, an estimated 3.3 million people were at risk of malaria in 2011, with population living in sub-Saharan Africa having the highest risk of acquiring malaria: approximately $80 \%$ cases and $90 \%$ deaths are estimated occur in WHO African region, with children less than five years of age and pregnant women most severely affected. Malaria was declared endemic in 104 countries in $2012^{[7]}$. In India, $P$ vivax is the commonest $(60-70 \%)$ followed by $\operatorname{Pf}(30-$ $45 \%$ ), $P$ malaria species is rarely found and $P$. Ovale is not reported in India ${ }^{[5]}$. The principal vectors, which cause malaria in India are the An culicifacies - a rural vector, An stephensi - an urban vector and An fluviatilis a resident of hilly forested areas. Total cases of malaria in 2010 were 1.49 million in which 0.78 million was of $P$ falciparum and total deaths were $767^{[7]}$.

Malaria is endemic in central and eastern Indian regions covering Madhya Pradesh, Jharkhand, Chhattisgarh, Orissa, West Bengal and Assam. Some reports show that the prevalence of malaria may shift from central Indian region to the south western coastal states of Maharashtra, Karnataka and Kerala ${ }^{[2]}$. Karnataka is one of the highest prevalent states in malaria cases. There were around 44122 total cases in $2010^{[8]}$.

Incidence of malaria has increases with the onset of the monsoon (June to October), due to water logging ${ }^{[8]}$. Morbidity pattern due to malaria is very high in Udupi district. Factors such as rapid urbanization, increased construction activities, influx of migratory workers were highlighted as the leading causes for the advent of malaria in the area ${ }^{[4]}$. The area is characterized by plentiful and regular seasonal rainfall, oppressive weather in hot months and high humidity throughout the year. Terrain and climatic conditions were highly conducive for malaria transmission in villages, towns and railway colonies all along the track. The scope of water stagnation and consequently mosquito breeding in and around depression near embankment, cutting sections, pipe and box culverts, drains of washing yards, abandoned masonry and curing tanks, overhead and septic tanks, depressions between two tracks at the stations were enormous to favour the mosquito proliferation round the year. Accelerated vector breeding and aggregation of tropical labour and movement of carriers (people with malaria infection - reservoir of infection) would establish indigenous transmission of malaria in the entire area ${ }^{[9]}$.

This study has a potential to bring forward possible suggestions addressing malaria in migrant families to spread awareness about the preventive measures, to maintain their personal hygiene and sanitation of the surroundings they are living in. The study aims to understand the environmental factors influencing malaria in migrant population.

\section{Materials And Methods:}

A descriptive quantative and qualitative descriptive study was conducted from June $21^{\text {st }}$ to September $25^{\text {th }}, 2013$ among migratory construction workers in and around Manipal, Karnataka, India. Study participants were migrant workers and their family members above the age of 18 years. A semi structured questionnaire was 
developed after literature review and experts opinion. The questions were translated into Hindi and local Kannada language to understand the environmental factors influencing malaria in migrant population. A snowball technique was used to find migrant construction workers along with convenient sampling .The quantitative data was entered and analyzed using SPSS version 15.0 and qualitative by thematic analysis.

\section{Results:}

1.1 Quantitative findings: The respondents were mainly from north-eastern states of India namely Bihar, Jharkhand, West Bengal and North Karnataka. The majority were males (64.4\%) as compared to females $(35.6 \%)$. The mean age of the male respondents were found to be $31.55( \pm 9.75)$ years and for female was $32( \pm 7.31)$ years. Most of the workers had income level of 200-400 INR/day.

Table1 shows the educational level among the respondents.

Table 2 shows the environmental factors influencing the malaria in Manipal.

\subsection{Qualitative findings:}

1.2.1Perception of migrant workers about malaria:

The worker in the different construction sites had varied perception of malaria. Almost every individual know about malaria, causes and its protective measures. The workers have heard about malaria via different sources such as advertisement in radio, posters, relatives, friends and health workers. Many out of them know the cause of malaria. The use of bed nets and coils were found to be unpopular because of less airflow due to which they feel hot. The other reason was they have to buy bed nets on their own which they cannot afford.

Most of the respondents felt that mosquitoes are found in construction sites but they don't have clear knowledge about breeding site of mosquitoes and its relation with environmental factors. They reported that mosquito bites usually at the night time during rainy season and after rainy season.

Prafulla (changed name) stated that many people come to ask problems from us but they never come back and do anything. The drainage system from the rich colonies come towards these slum areas and we are the suffer of that. There is no one behind us to stand.

\subsubsection{Observation made by interviewers:}

All the migrant workers were living in a very small kutcha house and the area was over-crowded. None of the hygiene facilities were availed by workers. Nobody was using bed nets and even if they are using it had big holes due to presence of rats. They clean only their own premises and don't care about their surroundings. Their no cleaning of garbage in dumping zone and moreover, the garbage was outside more than in dust bin. The migrant dwelling was in thick vegetation area which is major source of water stagnation. Almost every house roof top has tyres which is filled with water during rainy season and becomes breeding site for mosquitoes.

The migrant workers burn cow dunk cakes/ coal/wood in the evening time to produce smoke which is used to repel mosquitoes. Due to smoke many of the workers were suffering from respiratory problems. Residential area has large open tanks. These tanks are being used for daily activities and there is no proper dispensing system. Almost all the dwellings have common toilets where no hygiene practice has been followed. Open urination at the common place is done which act as breeding site. It was observed that many unused plastic pots, bottles; pits are filled with dirty water and food particles.

Many migrant workers live in the construction building itself. Water is being used thoroughly in those sites which lead to water stagnation.

\section{Conclusion and Discussion:}

Malaria among the construction migrant workers is major problem in the Manipal .Our qualitative and quantitative results found that water stagnation, bare soil, thick vegetation, open tanks, tyres, containers, garbage disposal, sewage disposal and sullage, high temperature, high humidity,pre and post rainy season are the major environmental factors that causes malaria. A study conducted by Kamath et al (2012) found that factors such as rapid urbanisation, increased construction activities and influx of migratory workers are leading cause for the advent of malaria in Manipal.Simalarly study conducted by Banjerjee et al (2013) found that knowledge and awareness regarding transmission and mode of infection is inadequate and the housing conditions of the migrant workers lack sanitary facilities ${ }^{[9]}$.

\section{Recommendation:}

- They should be given education regarding malaria and the environmental factors.

- Open pits should be filled with mud or treated with bleaching powder and the sanitation of the dwelling area should improve. 
- Existing services and preventive measures can be better utilized; barriers include:

-lack of awareness/knowledge about malaria (however, awareness was on avg. high)

-unawareness of health services in living quarters (e.g. health officer station)

-lack of resources (e.g. garbage removal, changing/cleaning water tanks more frequently)

- Regular inspection should be done of these sites by health workers.

- Outdoor spraying should be done on regular basis in thick vegetation area near the migrants settlement area.

\section{Limitations:}

For qualitative study it was difficult to interpret findings because of complex matters.

Small sample size

Snow ball convenient sampling method for quantitative data.

\section{Acknowledgement:}

Our amest gratitude to Department of Public Health, Manipal University and study participants for their co-operation. Special thanks go to Dr.Varalaxmi for her guidance during the entire study period.

\section{References:}

[1]. T Akenji, NN Ntonifor, MB Ndukum, H. Kimbi, EL Abongwa, A. Nkwescheu et al, Environmental factors affecting malarial prevalence in rural Bolifamba, South- West Cameroon, African Journal of Health Sciences, 13(1-2), 2006, 41-46.

[2]. S. Bhattacharya, C. Sharma, RC Dhiman, AP Mitra, Climate change and malaria in India, Current Sciences, 90(3), 2006, 369-75.

[3]. B Greenwood, T Mutabingwa, Malaria 2002, Nature 2002, 670-2.

[4]. R Kamath, S Gaitonde, P Tripathi, D Das, M Banerjee, M Shetty et al, Clinico-epidemiological profile of malaria: Analysis from a primary health health centre in Karnataka, Southern India. Global Journal Of Medicine And Public Health, 1(6) ,2012.

[5]. J. Kishore., National Vector Borne Disease Control Program(10 Ed.), National Health Programs of India (New Delhi (India): Century Publications, 2012) 330-368.

[6]. SB Roy, RR Sarkar, S Sinha, Theoretical investigation of malarial prevalence in two Indian cities using the response surface method. Malarial Journal 2011, 1-12.

[7]. World Malaria Report 2012 [Online]. 2012 [cited 2013 Mar 21]; Available from: URL:http://www.who.int/malaria/publications/world_malaria report_2012/wmr2012 full_report.pdf

[8]. Kakkilaya BS. Malaria in India [online]. [2004?]. [cited 2013 mar 22];[1 screen]. Available from: URL:http://www.malariasite.com/malaria/MalariaInIndia.htm

[9]. Health Impact Assessment (HIA) of Development Projects with Reference to Mosquito-borne Diseases, A Profile of National Institute of Malaria Research.

[10]. M. Banjerjee, AS Dhakar, S Singh, Qualitative assessment regarding malaria knowledge, attitude and risks among migrant construction workers at construction areas and migratory settlements in Udupi taluk, Karnataka, India, International Journal of Basic and Applied Medical Sciences, 3(1), 2013, 29-36.

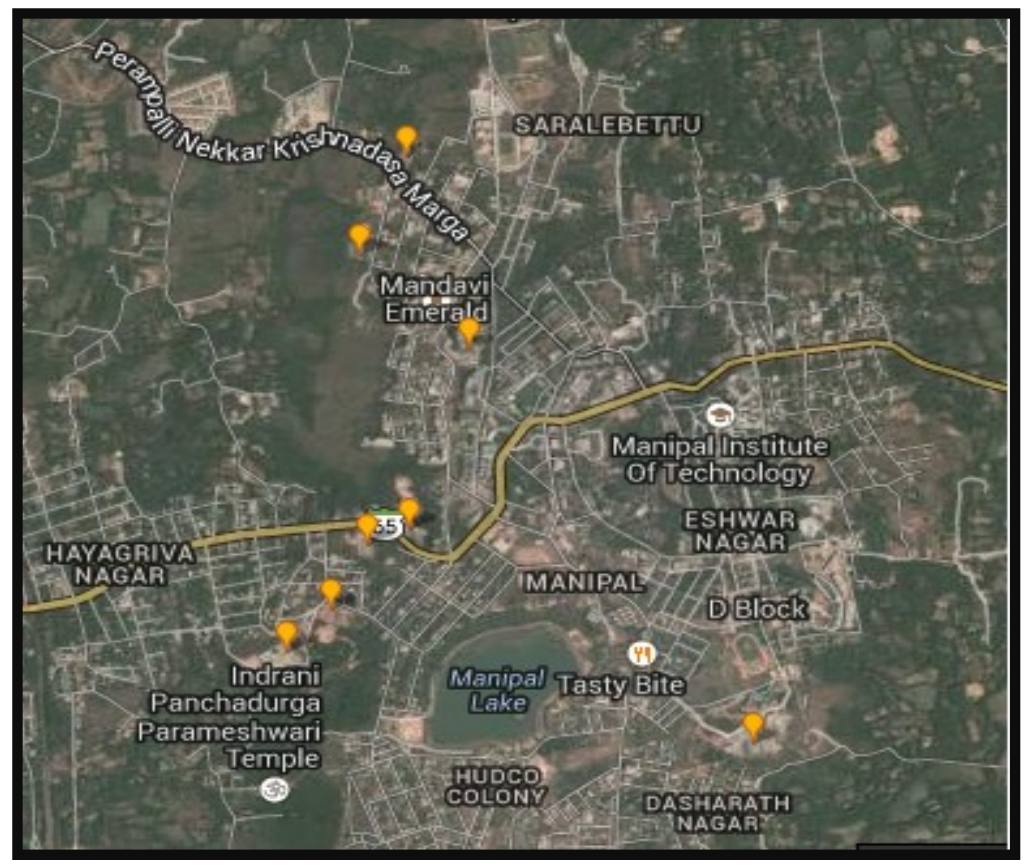

Fig.1: Showing the marked construction site in and around Manipal. 


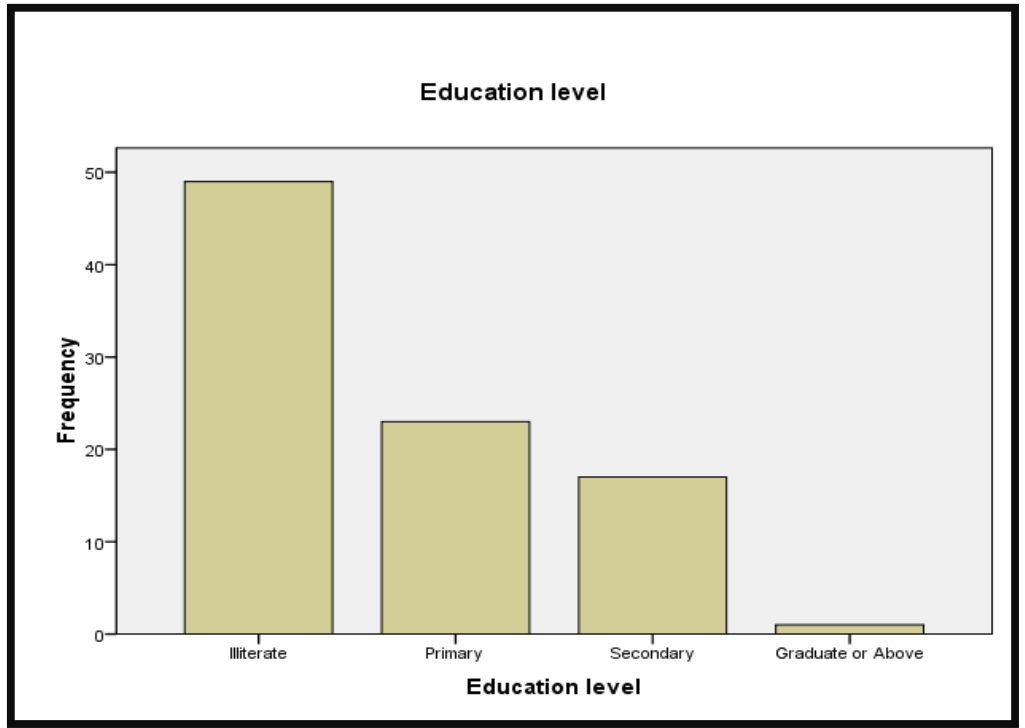

Table 1: Educational status of migrant workers

Table:2 Environmental factors influencing malaria in migrant dwelling site

\begin{tabular}{lll} 
Variables & Yes $(\%)$ & No(\%) \\
\hline Water stagnation & 100 & 0 \\
\hline Bare soil & 97.8 & 2.2 \\
\hline Thick vegetation & 67.8 & 32.2 \\
\hline Open tanks & 74.4 & 25.6 \\
\hline Tyres & 48.9 & 51.1 \\
\hline Containers & 100 & 0 \\
\hline Garbage disposal & 100 & 0 \\
\hline Open drains & 90.0 & 10.0 \\
\hline Sewage disposal & 72.2 & 27.8 \\
\hline Sullage disposal & 84.4 & 15.6 \\
\hline
\end{tabular}

